\title{
Gastrointestinal Tract: A Neglected Guardian Angel?
}

\author{
Amol T Kothekar ${ }^{1}$, Atul P Kulkarni ${ }^{2}$
}

\begin{abstract}
Role of the gastrointestinal (Gl) system is not limited to the digestion of food and absorption of water and nutrients. Gastrointestinal mucosa forms a barrier preventing translocation of microbes into the blood. Upper GI tract performs important function of swallowing and prevention of aspiration, failure of which mandates enteral tube feeding. Rate of gastric emptying depends on gastric volume and contents and delayed emptying is observed both in solid and in fatty food. Cricoid pressure during intubation is an important intervention for prevention of aspiration in critically ill patients who are considered as full stomach. To utilize mucosal barrier function optimally, hemodynamically stable patients should preferably receive enteral nutrition even if they are on small doses of vasopressors. Post-pyloric feeds may reduce risk of aspiration and hence are recommended for patients who are deemed to have high risk for aspiration. Bowel sounds have poor reproducibility, sensitivity, specificity, accuracy, and interobserver agreement, and absent bowel sounds should not be considered as a contraindication to enteral feeding. Keywords: Aspiration pneumonia, Bowel sounds, Cricoid pressure, Enteral nutrition, Gastric emptying, Gastric motility, Paralytic ileus, Physiology of gastrointestinal tract, Trophic feeding.

Indian Journal of Critical Care Medicine (2020): 10.5005/jp-journals-10071-23616
\end{abstract}

\section{INTRODUCTION}

The digestive system comprises the gastrointestinal (GI) tract from oral cavity to anal canal with the accessory organs including teeth, tongue, and the glands such as salivary gland, liver, gallbladder, and pancreas. It plays a pivotal role in not only in the digestion of food, absorption of water and nutrients, and excretion of waste products, but the mucosa also forms a barrier, which prevents translocation of microbes into the blood. We will focus on important physiological functions of $\mathrm{Gl}$ tract relevant to critical care.

\section{Swallowing and Prevention of Aspiration Swallowing}

Swallowing is a complex process involving various cranial nerves, such as trigeminal (V), facial (VII), glossopharyngeal (IX), vagus (X), accessory (XI), and hypoglossal (XII), and more than 50 muscles. ${ }^{1}$ It can be divided into four stages: the oral preparatory phase, oral transit stage, pharyngeal phase, and esophageal stage.

\section{Oral Preparatory Phase}

In this voluntary phase, solids and liquids and saliva are prepared into a consistency which allows smooth transit. Tongue (XII) helps in movement of food to the teeth which play important role in mastication (V), while appropriate lip seal (VII) prevents spillage of food. ${ }^{2}$

\section{Oral Phase}

In this phase, the food is moved to the posterior part of the oral cavity with the help of the tongue (XII).

\section{Pharyngeal Phase}

The third phase is the most important for protecting the airway from aspiration. It is reflex process that transports the food through the pharynx to the esophagus, avoiding entry of food in the nasopharynx or larynx (IX-XI). Closure of the nasopharynx by the soft palate prevents entry of food in nasopharynx. Hyoid bone is elevated causing superior and anterior movement of larynx. At the same time, the epiglottis moves downward directing the

\begin{abstract}
1,2Division of Critical Care Medicine, Department of Anesthesia, Critical Care and Pain, Tata Memorial Center, Homi Bhabha National Institute, Mumbai, Maharashtra, India

Corresponding Author: Atul P Kulkarni, Division of Critical Care Medicine, Department of Anesthesia, Critical Care and Pain, Tata Memorial Hospital, Homi Bhabha National Institute, Mumbai, Maharashtra, India, Phone: +91 9869077526, e-mail: kaivalyaak@ yahoo.co.in

How to cite this article: Kothekar AT, Kulkarni AP. Gastrointestinal Tract: A Neglected Guardian Angel? Indian J Crit Care Med 2020; 24(Suppl 4):S146-S151.

Source of support: Nil

Conflict of interest: None
\end{abstract}

food bolus away from the larynx toward the posterior pharynx. Additionally, laryngeal inlet is protected by adduction of true and false vocal folds (superior and recurrent laryngeal nerves $\mathrm{X}$ ). Closure of laryngeal inlet causes obligatory period of apnea lasting 1 to 2 seconds. Inferior pharyngeal constrictor or cricopharyngeus muscle (upper esophageal sphincter) relaxes to allow the food to pass into esophagus.

Tachypneic patients may be unable to hold breath for the "obligatory period of apnea" during pharyngeal phase of swallowing, increasing risk of aspiration. It is prudent therefore to withhold oral intake. This also helps in reducing gastric residual volume, preventing aspiration during intubation, if it becomes necessary.

\section{Esophageal Phase}

This reflexive stage transports the food by the esophageal peristaltic movement and relaxation of the lower esophageal sphincter (LES) into the stomach (IX, XI). The primary peristaltic wave occurs throughout the esophagus till LES during swallowing. Secondary peristaltic waves are initiated locally when the food bolus stretches the esophageal wall. Depending on the size of food bolus, this phase may take 8 to 20 seconds in normal individuals. ${ }^{2}$ 


\section{Swallowing Dysfunction and Aspiration Risk}

Swallowing may be impaired in critically ill patients due to various reasons. Patients with altered sensorium or those who are deeply sedated and paralyzed, or nursed in supine position, may have gastroesophageal reflux, making them vulnerable to aspiration. Patients with critical illness polyneuromyopathy may have dysphagia due to dysfunctional oropharyngeal and laryngeal sensation, reduced cough strength, and limited glottic clearance. Incidence of swallowing disorders, in recently extubated patients, ranges from 15 to $50 \%{ }^{2}$

Such dysphagia patients may exhibit typical signs or symptoms of aspiration, especially when consciousness and sensory input are intact. These include pain or coughing while swallowing, the sensation of food getting stuck in the throat or regurgitation, a hoarse or wet voice after eating, or the sensation of regurgitation. On the other hand, nearly half the patients with documented aspiration lack any of these presenting clues and therefore are said to have silent aspiration. ${ }^{2}$

Arytenoid cartilage is vulnerable to displacement due to its mobile nature and small articulating surface. Patients with difficult intubation with repeated or prolonged attempts for intubation are at risk for aspiration after extubation due to impaired glottic closure secondary to arytenoid subluxation. Another risk factor for arytenoid subluxation is unplanned extubation with trauma due to partially inflated cuff.

Patients undergoing posterior fossa surgery are known to have both preexisting and postoperative lower cranial nerve dysfunctions, leading to loss of the gag reflex and aspiration pneumonitis. ${ }^{3}$ Incidence of aspiration after posterior fossa surgery is 40-70\%. ${ }^{4}$ Dysphagic patients are at risk of aspiration and subsequent acute respiratory failure. Insertion of feeding tubes bypasses the need for swallowing and can help in providing nutrition. Once the patients improve, oral feeding should be encouraged.

\section{Gastric Emptying ${ }^{5}$}

\section{Gastric Secretion, Gastric Emptying, and Aspiration Risk}

Stomach secretes about $1.5 \mathrm{~L}$ of acidic ( $\mathrm{pH}$ 1-3.5) gastric juice in a day. Table 1 summarizes the composition, volume and function of secretions of various parts of GI tract. Additionally, majority of the saliva is swallowed and finally absorbed in stomach. The rate of gastric emptying depends on the nature (solid vs liquid) and volume of the gastric contents. After a typical solid meal, there is a lag period of 20 to 30 minutes with no gastric emptying, which allows mixing of food with gastric secretions (Fig. 1). This is followed by linear emptying of solid gastric contents. Presence of fat in solid feed is known to delay gastric emptying. Clear liquids do not have a lag phase and have initial faster clearance due to exponential rate of emptying. However, if hyperosmolar, acidic, or fatty liquids are consumed, the emptying is delayed and takes as long as solids. Preoperative fasting guidelines for "healthy" patients undergoing elective procedures are based on these observations. Usual recommendation is clear liquids may be ingested for up to two hours and light meal up to six hours of elective procedure. ${ }^{6,7}$ Fasting of eight hours or more is required for fried or fatty foods and in presence of meat.

It is important to note that further delay in gastric emptying is common in trauma and critical illness. As the procedure of intubation is seldom elective the ICU, it is therefore prudent to consider all such patients as having full stomach and take appropriate precautions to prevent aspiration.

\section{Lower Esophageal Sphincter and Barrier Pressure at the Gastroesophageal Junction}

Lower esophageal sphincter (LES), a physiological sphincter, is located in the distal $2-4 \mathrm{~cm}$ to the esophagus. At "rest," LES is closed with pressure of $20-30 \mathrm{~mm} \mathrm{Hg}$. Simultaneous normal intragastric pressure is $5-10 \mathrm{~mm} \mathrm{Hg}$. The difference between LES and intragastric pressure is known as the "Barrier Pressure" and is the primary determinant of regurgitation of gastric contents in the esophagus. Barrier pressure is reduced during pregnancy and hiatus hernia, increasing risk of aspiration. Drugs like volatile anaesthetics, propofol, thiopentone, opioids, atropine, glycopyrrolate, and alcohol reduce barrier pressure by decreasing LES tone. On the other hand, metoclopramide, suxamethonium, and anticholinesterases increase LES tone. Conditions causing raised abdominal pressure, such as obesity, abdominal tumor, intra-abdominal hypertension and gravid uterus, reduce barrier pressure by increasing intragastric pressure.

Cricoid cartilage is a complete cartilage and circular in shape, without the posterior membranous part (pars membranacea) which is present in other tracheal cartilages, and force applied to it closes upper esophagus. In a cadaveric study, $30 \mathrm{~N}$ of cricoid force exerted esophageal pressures of up to $40 \mathrm{~mm} \mathrm{Hg} .{ }^{8}$ Maximum gastric pressure of observed in the study was $35 \mathrm{~mm} \mathrm{Hg}$, when stomach was distended by volume of $750 \mathrm{~mL}$. Application of cricoid pressure may be counterproductive, as it has shown to decrease barrier pressure by reducing lowering LES tone. ${ }^{9}$ Moreover, it may cause problems during mask ventilation and intubation. ${ }^{10}$ Despite the conflicting evidence, a rapid sequence induction with cricoid pressure is the standard of care for patients who are considered high risk for aspiration, due to lack of alternative.

\section{Gut Mucosal Barrier System: Effect of FEeding AND Vasopressors}

The human intestine, especially the large intestine, contains huge numbers of microorganisms. While most of them are symbiotic in nature, few may be pathogenic. Gut mucosal barrier system effectively keeps these organisms away from the systemic circulation. These barriers include production of mucus and microbicidal and antiviral agents, such as a defensins, cryptodins, lysozymes, and secretory phospholipase A2 (sPLA2). Secretory $\lg A(\lg A)$ provides an immune defense against the specific intraluminal microorganisms. ${ }^{11}$ The mucosa is a single layer of closely bound cells with tight junctions impermeable to pathologic luminal substances. This layer has high turnover and the whole cell line is replaced every 5 to 7 days. Mucin, the principle ingredient of gut mucous, creates a physical barrier to the luminal microorganisms. The antimicrobial substances in the mucin-like lactoferrin, lysozymes, and secretory phospholipase 2 (sPLA2) destroy the bacterial cell wall, and the lactoferrin prevents the bacteria from adhering to the cells. Stressful conditions (critical illness and reduction in normal oral intake) weaken this defense system, making the host vulnerable to microbial invasion. Early enteral nutrition (EN) may partly reverse this breach in the gut mucosal barriers system (see below).

\section{Effect of Vasopressors on Splanchnic Circulation and Effects of EN}

Vasopressors divert blood away from splanchnic circulation to the vital organs. Epinephrine impairs splanchnic circulation in 
Table 1: Gastrointestinal secretions volume, contents and functions (adapted from ref. 5)

\begin{tabular}{|c|c|c|c|c|c|c|}
\hline Organ & Secretion & $\begin{array}{l}\text { Volume output } \\
\text { per day in } \mathrm{mL}\end{array}$ & $\mathrm{pH}$ & Digestive enzymes & Other contents & Important function \\
\hline \multirow[t]{2}{*}{ Mouth } & \multirow[t]{2}{*}{ Saliva } & \multirow[t]{2}{*}{1,000} & \multirow[t]{2}{*}{$6.0-7.0$} & \multirow[t]{2}{*}{$\begin{array}{l}\text { Mucin, haptocorrin } \\
\text { (R-protein), a-amylase } \\
\text { lingual lipase }\end{array}$} & \multirow{2}{*}{$\begin{array}{l}\text { Thiocyanate, } \\
\text { lysozyme, lactofer- } \\
\text { rin and immuno- } \\
\text { globulin A. }\end{array}$} & $\begin{array}{l}\text { Lubrication of food, } \\
\text { Initiation of starch diges- } \\
\text { tion by a-amylase }\end{array}$ \\
\hline & & & & & & $\begin{array}{l}\text { Haptocorrin (R-protein) } \\
\text { binds to vitamin B12, } \\
\text { protecting it from the } \\
\text { low-pH environment of } \\
\text { the stomach. }\end{array}$ \\
\hline \multirow[t]{3}{*}{ Stomach } & \multirow[t]{3}{*}{ Gastric juices } & \multirow[t]{3}{*}{1500} & \multirow[t]{3}{*}{$1.0-3.5$} & \multirow[t]{3}{*}{$\begin{array}{l}\text { Hydrochloric acid }(\mathrm{HCl}) \text {, } \\
\text { Pepsinogen* }\end{array}$} & \multirow[t]{3}{*}{$\begin{array}{l}\text { Intrinsic factor (IF) } \\
\text { Mucus }\end{array}$} & $\begin{array}{l}\text { Micro-biocidal effect on } \\
\text { the swallowed food and } \\
\text { saliva }\end{array}$ \\
\hline & & & & & & Digestion of proteins \\
\hline & & & & & & $\begin{array}{l}\text { Activation of Pepsinogen } \\
\text { protection of the gastric } \\
\text { mucosa from acid }\end{array}$ \\
\hline Duodenum & Brunner's gland & 200 & $8.0-8.9$ & & $\begin{array}{l}\text { Mucus } \\
\text { Sodium bicarbo- } \\
\text { nate }\left(\mathrm{NaHCO}_{3}\right)\end{array}$ & $\begin{array}{l}\text { Protection of the duo- } \\
\text { denal wall from highly } \\
\text { acidic gastric juice }\end{array}$ \\
\hline Pancreas & $\begin{array}{l}\text { Pancreatic } \\
\text { secretion }\end{array}$ & 1000 & $8.0-8.3$ & $\begin{array}{l}\text { Proteins: trypsin, } \\
\text { chymotrypsin, and } \\
\text { carboxypolypeptidase; } \\
\text { Carbohydrates: amylase } \\
\text { (pancreatic), fat, lipase } \\
\text { (pancreatic), cholesterol, } \\
\text { esterase, phospholipase }\end{array}$ & & $\begin{array}{l}\text { Digestion of proteins, fat } \\
\text { and carbohydrates }\end{array}$ \\
\hline $\begin{array}{l}\text { Liver and } \\
\text { gallbladder }\end{array}$ & Bile & 1,000 & 7.8 & - & $\begin{array}{l}\text { Bile salts } \\
\text { Bilirubin } \\
\text { Lecithin }\end{array}$ & $\begin{array}{l}\text { Bile salts act as surfactant } \\
\text { and emulsify large fat } \\
\text { particles and help in ab- } \\
\text { sorption of digested fat }\end{array}$ \\
\hline $\begin{array}{l}\text { Small intestine } \\
\text { (Crypt of } \\
\text { Lieberkühn) }\end{array}$ & $\begin{array}{l}\text { Small intestine } \\
\text { secretions }\end{array}$ & 1,800 & $7.5-8.0$ & - & & $\begin{array}{l}\text { Watery vehicle for } \\
\text { absorption of digested } \\
\text { nutrients from chyme }\end{array}$ \\
\hline $\begin{array}{l}\text { Small intestine } \\
\text { (Mucosal } \\
\text { enterocytes } \\
\text { covering the } \\
\text { villi) }\end{array}$ & $\begin{array}{l}\text { Intracellular } \\
\text { enzymes, not } \\
\text { secreted in the } \\
\text { lumen }\end{array}$ & - & - & $\begin{array}{l}\text { Peptidases } \\
\text { Disaccharidases (sucrase, } \\
\text { maltase, isomaltase, and } \\
\text { lactase) } \\
\text { Lipase (intestinal) }\end{array}$ & & $\begin{array}{l}\text { Splitting of small } \\
\text { peptides into amino } \\
\text { acids disaccharides into } \\
\text { monosaccharides neutral } \\
\text { fats into glycerol and } \\
\text { fatty acids }\end{array}$ \\
\hline \multirow[t]{5}{*}{ Large intestine } & \multirow[t]{5}{*}{$\begin{array}{l}\text { Large intestine } \\
\text { secretions }\end{array}$} & \multirow[t]{5}{*}{200} & \multirow[t]{5}{*}{$7.5-8.0$} & & \multirow[t]{5}{*}{$\begin{array}{l}\text { Mucus } \\
\text { Sodium } \\
\text { bicarbonate }\end{array}$} & $\begin{array}{l}\text { Mucus: } \\
\text { Protection of the } \\
\text { intestinal wall against } \\
\text { excoriation }\end{array}$ \\
\hline & & & & & & Fecal matter adhesive \\
\hline & & & & & & Bacterial barrier \\
\hline & & & & & & $\mathrm{NaHCO}_{3}:$ \\
\hline & & & & & & $\begin{array}{l}\text { Protection of the } \\
\text { intestinal wall against } \\
\text { fecal acids }\end{array}$ \\
\hline
\end{tabular}

*Most of the enzymes are secreted in inactive form, which are activated in the gut lumen

severe septic shock, while dopamine and norepinephrine have minimal effects. ${ }^{12}$ Sympathomimetic vasopressors inhibit gastric and bowel motility. Presence of nutrients in the bowel lumen may increase mucosal energy expenditure and oxygen requirements. Food can increase splanchnic blood flow by $>40 \%$ and intestinal microcirculation by up to $60 \%$. EN reverses the lipopolysaccharide infusion-induced splanchnic ischemia in endotoxic canine model. A steal phenomenon is possible here, as redistribution of cardiac output to the splanchnic circulation is not associated with increase in cardiac output. There are reports of ischemic necrosis 


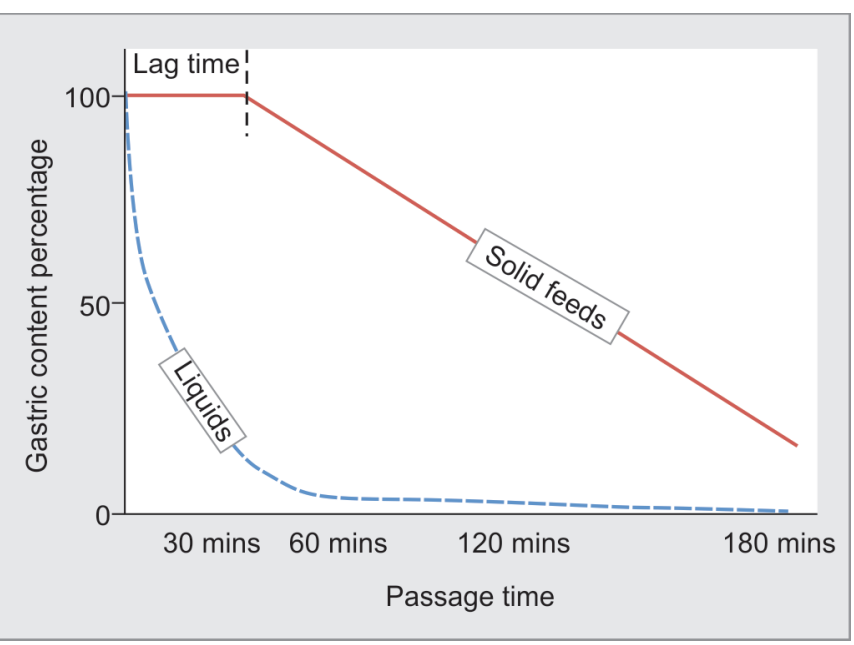

Fig. 1:Time taken for gastric passage by solid feeds and liquids (adapted from ref. 5)

of bowel with EN in burn patients with ARDS and sepsis. ${ }^{13} \mathrm{EN}$ in hemodynamic unstable patient with ischemic small bowel can worsen the ischemia causing necrosis and can lead to bacterial overgrowth.

Khalid et al. in their retrospective analysis of prospectively collected multi-institutional medical ICU data of 1,174 patients found that early feeding was more beneficial in the sickest patients treated with multiple vasopressors. ${ }^{14}$ In patients with acute respiratory distress syndrome requiring ventilation, giving trophic feeds (10-20 kcal/hour or up to $500 \mathrm{kcal} /$ day for 6 days) were as good as full feeds in terms of ventilator-free days and 60 -day mortality. ${ }^{15}$ Moreover, trophic feeds reduced incidence of $\mathrm{GI}$ intolerance.

Based on understanding of physiology and current evidence, mere requirement of vasopressor need not be looked upon as contraindication to EN. Feeding should be obviously deferred in patients on very high or escalating doses of vasopressors (noradrenaline $1 \mathrm{Ug} / \mathrm{kg} /$ minute for example) with ongoing shock, hypotension, or signs of organ hypoperfusion. Once initial shock is resolved, and the patient is stable on vasopressors, EN (trophic, if full feeds not possible) should be started as early as possible and gradually escalated.

\section{Gastrointestinal Motility ${ }^{16}$}

Gastrointestinal tract has three layers of smooth muscle: the outer longitudinal layer, the middle circular layer, and the inner submucosal layer. The enteric nervous system (ENS) comprises the myenteric plexus located between circular and longitudinal layers and the submucosal plexus found between circular and submucosal layers (Fig. 2).

Gastrointestinal tract distal to esophagus exhibits baseline electric activity in the form of spontaneous variations in transmembrane potential between -70 and $-40 \mathrm{mV}$ in resting (fasting) period, which is known as basal electrical rhythm (BER). At threshold of $-40 \mathrm{mV}$ or higher, spike-burst activity with smooth muscle contraction is observed due to sudden influx of sodium and calcium ions, and this is associated with smooth muscle contraction. Endogenous adrenaline and exogenous vasopressors have an inhibitory effect on gut motility due to hyperpolarization of the cell membrane and reduced spike-burst activity. Peristalsis is a reflex response to a gut wall stretch that causes contraction at the

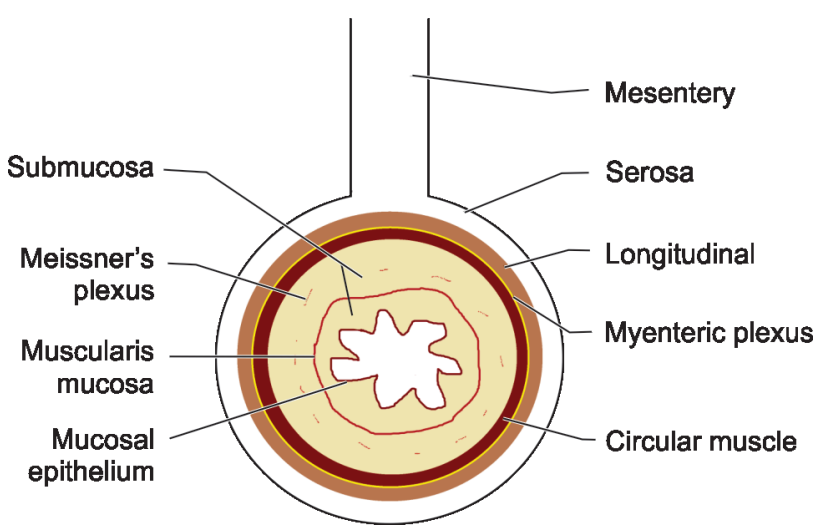

Fig. 2: Gut wall layers and the nervous system (adapted from ref. 16)

level of stretch and the proximal part. Relaxation of distal lumen ensures distal movement of the contents. Peristaltic wave ensues distal passage of food.

Stomach is a unique part of the Gl system which performs function of food storage, digestion, and gradual release in the intestines.

\section{Function in Fasting State}

Stomach has the fasting motility pattern known as the migrating motor complex (MMC), in which myoelectrical impulses move caudally from stomach up to the distal ileum. MMC probably contributes to the clearance of luminal contents of stomach and small intestine in preparation of next meal.

\section{Function in Fed State}

The proximal zone of the stomach; formed by the fundus and proximal third of the corpus of the stomach, act as a reservoir. The distal zone formed by the antrum and pylorus of stomach, as well as proximal duodenum performs two functions; antrum grinds and sieves solid food whereas pylorus along with the proximal duodenum delivers chyme (pulpy food mixed with gastric juice) at a fixed rate into the small intestine. ${ }^{17}$ Gastrointestinal tract motility disorders are frequently observed in critically ill patients and primarily affect stomach with relative sparing of small intestine. ${ }^{18}$ Both proximal and distal stomach including the antrum frequently suffer disturbed peristaltic function leading to delayed gastric emptying. Factors that contribute to abnormal GI motility include drugs such as opioids and catecholamines, metabolic abnormalities like hypokalemia, hyperglycemia (glucose $>140 \mathrm{mg} / \mathrm{dL}$ ), direct surgical insult, or hypoperfusion, increased intra-cranial pressure, sepsis, etc. ${ }^{17}$ Morphine is known to shorten fasting migrating motor complex and to cause delay in conversion to normal postprandial pattern in stomach in response to feeding.

\section{Physiology of Pre- and Post-pyloric FEEDING}

Pre-pyloric feeding in the form of nasogastric or orogastric tube is commonly used in ICU in critically ill patients. Occurrence of delayed gastric emptying (gastroparesis) with relative preservation of small bowel function in this population has created potential for small bowel feeding via a nasojejunal tube. Other indications of post-pyloric feeding include gastric outlet obstruction, recurrent aspirations, severe pancreatitis, hyperemesis gravidarum, proximal enteric fistula, and postoperative anastomotic gastroenteric stenosis. ${ }^{19}$ 
Physiological effects of intra-jejunal feeding are different from intra-gastric and intra-duodenal feeding. Compared to intra-duodenal feeding, intra-jejunal feeding is associated with less stimulation of pancreatico-biliary secretions and gallbladder motility and less likelihood of aspiration or vomiting. ${ }^{19}$ Stomach has good food storing capacity; hence, either bolus or continuous feeds can be given. On the contrary, both jejunum and duodenum lack food storing capacity hence only continuous feeds can be given. Jejunum and duodenum are designed to accept on controlled delivery of isotonic food. Hence, rapid infusion or bolus of a hyperosmotic feed may not be tolerated by the patient and can cause abdominal cramping, hyperperistalsis, and diarrhea.

A meta-analysis of 1,109 patients in 14 studies comparing gastric vs post-pyloric feeding has shown relative risk reduction of 0.65 (Cl: $0.51,0.84)$ in development of pneumonia. ${ }^{18}$ However, for post-pyloric tube placement, there is significant delay in initiation of feeding and need for more expertise, equipment and higher cost of consumables. Significant benefits in terms of mortality, ICU length of stay (LOS), hospital LOS, duration of mechanical ventilation, are lacking with post-pyloric feeding. ${ }^{18}$ In patients at high risk for aspiration, post-pyloric feeding is recommended. ${ }^{20}$

\section{Physiology of Bowel Sounds}

Critically ill patients are at risk of development of multiple $\mathrm{Gl}$ disorders like gut ischemia diverticulitis, or peritonitis needing laparotomy and also ileus due to bowel handling and medications like opiates. It is a common to carry out auscultation of abdomen for bowel sounds. Many clinicians withhold EN if bowel sounds are absent; however, this practice is questionable.

The movement of gas and fluids produces bowel sounds or borborygmi during peristalsis. Gas in the GI tract comes either from swallowed air or from the food during the process of digestion. The former component is largely absent in mechanically ventilated patients on tube feeds, and the intake of latter is often reduced in critically ill patients. Unlike cardiac or respiratory sounds, bowel sounds are not rhythmic, predictable, or reproducible. Normal bowel sounds occur intermittently and irregularly approximately 5-35 times a minute. The minimum period of auscultation to safely conclude absence of bowel sound can range from 30 seconds to 7 minutes. ${ }^{21}$ Overall sensitivity, specificity, accuracy, and interobserver agreement of bowel sounds are very poor; hence, caution should be exercised in making clinical decisions based on assessment of bowel sounds.

Guidelines as old as published in 2003 do not consider absent bowel sounds as a contraindication to enteral feeding! ${ }^{22}$ However, the dogmatic practice of holding enteral feeding till auscultation of the bowel sounds continues, and refuses to die!!

\section{ConcLusion}

Understanding of gastrointestinal tract physiology is important for management of critically ill patients. Enteral tube feeds rather than oral feeds should be given in patients with impaired swallowing. Gastric emptying is faster for clear liquids and slower for solids, especially with fatty food. Pressure on cricoid cartilage may close upper esophagus upon pressure and is used for aspiration prevention during intubation. Once hemodynamically stable, patients should preferably receive enteral nutrition to maintain gut mucosal barrier function even if on small doses of vasopressors. Post-pyloric feeds may reduce risk of aspiration and hence are recommended for patients who are deemed to have high risk for aspiration. Bowel sounds have poor reproducibility, sensitivity, specificity, accuracy, and interobserver agreement, hence absent bowel sounds should not be considered as a contraindication to enteral feeding.

\section{References}

1. Melciades Barbosa. CM. Neural control of swallowing. Arq Gastroenterol [Internet] 2018;55(Suppl 1):61-75. Available from: http://www.scielo.br/scielo.php?script=sci_arttext\&pid=S000428032018000500061\&Ing=en. 10.1590/s0004-2803.201800000-45.

2. Macht M, Wimbish T, Bodine $C$, Moss M. ICU-acquired swallowing disorders. Crit Care Med 2013;41(10):2396-2405. DOI: 10.1097/ CCM.0b013e31829caf33.

3. Jagannathan S, Krovvidi H. Anaesthetic considerations for posterior fossa surgery. Contin Edu Anaesth Crit Care Pain 2014;14(5):202-206. DOI: 10.1093/bjaceaccp/mkt056.

4. Ram Z, Grossman R. Dysphagia as a complication of posterior fossa surgery in adults. World Neurosurg 2014;82(5):625-626. DOI: 10.1016/j.wneu.2013.02.045.

5. Chambers D, Huang CL-H, Matthews G. Stomach and vomiting. Basic physiology for anaesthetists. Cambridge, United Kingdom: Cambridge University Press; 2019. pp. 283-288.

6. Practice guidelines for preoperative fasting and the use of pharmacologic agents to reduce the risk of pulmonary aspiration: application to healthy patients undergoing elective procedures: an updated report by the american society of anesthesiologists task force on preoperative fasting and the use of pharmacologic agents to reduce the risk of pulmonary aspiration. Anesthesiology 2017;126(3):376-393. DOI: 10.1097/ALN.0000000000001452.

7. Hall JE. Secretory functions of the alimentary tract. Guyton and Hall textbook of medical physiology. Philadelphia, PA: Elsevier; 2021. p. 807-822.

8. Vanner RG, Pryle BJ. Regurgitation and oesophageal rupture with cricoid pressure: a cadaver study. Anaesthesia 1992;47(9):732-735. DOI: 10.1111/j.1365-2044.1992.tb03248.x.

9. Tournadre JP, Chassard D, Berrada KR, Boulétreau P. Cricoid cartilage pressure decreases lower esophageal sphincter tone. Anesthesiology 1997;86(1):7-9. DOI: 10.1097/00000542-199701000-00003.

10. Ramez Salem M, Khorasani A, Zeidan A, Crystal GJ. Cricoid pressure controversies: narrative review. Anesthesiology 2017;126(4):738-752. DOI: https://doi.org/10.1097/ALN.0000000000001489.

11. Fukatsu K, Kudsk KA. Nutrition and gut immunity. Surg Clin North Am 2011;91(4):755-770. , vii. 10.1016/j.suc.2011.04.007.

12. De Backer D, Creteur J, Silva E, Vincent JL. Effects of dopamine, norepinephrine, and epinephrine on the splanchnic circulation in septic shock: which is best? Crit Care Med 2003;31(6):1659-1667. DOI: 10.1097/01.CCM.0000063045.77339.B6.

13. McClave SA, Chang WK. Feeding the hypotensive patient: does enteral feeding precipitate or protect against ischemic bowel? Nutr Clin Pract 2003;18(4):279-284. DOI: 10.1177/0115426503018004279.

14. Khalid I, Doshi P, DiGiovine B. Early enteral nutrition and outcomes of critically ill patients treated with vasopressors and mechanical ventilation. Am J Crit Care 2010;19(3):261-268. DOI: 10.4037/ ajcc2010197.

15. Rice TW, Wheeler AP, Thompson BT, Steingrub J, Hite RD, Moss M, et al., National Heart, Lung, and Blood Institute Acute Respiratory Distress Syndrome (ARDS) Clinical Trials Network Initial trophic vs full enteral feeding in patients with acute lung injury: the EDEN randomized trial. JAMA 2012;307(8):795-803. DOI: 10.1001/jama.2012.137.

16. Hall JE. General principles of gastrointestinal function. Guyton and Hall Textbook of Medical Physiology. Philadelphia, PA: Elsevier; 2021. pp. 787-796.

17. Ladopoulos T, Giannaki M, Alexopoulou C, Proklou A, Pediaditis E, Kondili E. Gastrointestinal dysmotility in critically ill patients. Ann Gastroenterol 2018;31(3):273-281. DOI: 10.20524/aog.2018.0250. 
18. Alkhawaja S, Martin C, Butler RJ, Gwadry-Sridhar F. Post-pyloric versus gastric tube feeding for preventing pneumonia and improving nutritional outcomes in critically ill adults. Cochrane Database Syst Rev 2015;2015(8):CD008875. DOI: 10.1002/14651858.CD008875.pub2.

19. Niv E, Fireman Z, Vaisman N. Post-pyloric feeding. World J Gastroenterol 2009;15(11):1281-1288. DOI: 10.3748/wjg.15.1281.

20. McClave SA, Taylor BE, Martindale RG, et al. Guidelines for the provision and assessment of nutrition support therapy in the adult critically ill patient: Society of Critical Care Medicine (SCCM) and American Society for Parenteral and Enteral Nutrition (A.S.P.E.N.). JPEN J Parenter Enteral Nutr 2016;40(2):159-211. DOI: 10.1177/0148607115621863.

21. Elhardello O, Bowel Sounds MJ. Is it time for surgeons to hang-up their stethoscopes? World J Surg Surgical Res 2018;1:1066.

22. Stroud M, Duncan H, Nightingale J. British Society of Gastroenterology. Guidelines for enteral feeding in adult hospital patients. Gut 2003;52(Suppl 7):vii1-vii12. DOI: 10.1136/gut.52. suppl_7.vii1. 